\title{
Debundling and Selective Enrichment of SWNTs for Applications in Dye-Sensitized Solar Cells
}

\author{
F. Bonaccorso \\ Engineering Department, University of Cambridge, Cambridge CB3 OFA, UK \\ Correspondence should be addressed to F. Bonaccorso, fb296@cam.ac.uk \\ Received 31 December 2009; Accepted 8 April 2010 \\ Academic Editor: Gaetano Di Marco
}

Copyright ( $) 2010$ F. Bonaccorso. This is an open access article distributed under the Creative Commons Attribution License, which permits unrestricted use, distribution, and reproduction in any medium, provided the original work is properly cited.

We present an overview of the recent developments in de-bundling and sorting of Single-Wall Carbon Nanotubes (SWNTs), which are useful for hi-tech applications in dye sensitized solar cells (DSSCs). Applications of SWNTs as transparent and conductive films, catalyst, and scaffold in DSSCs are also reviewed.

\section{Introduction}

The direct utilization of solar radiation to produce electricity in photovoltaic (PV) devices is at the centre of an ongoing research effort to utilize the renewable energy. Silicon $(\mathrm{Si})$ is by far the most widely used absorber and currently dominates the market of PV devices [1]. Despite significant development over the past decades, the high cost of Si-based solar cells is a bottleneck for the implementation of solar electricity on large scale. The development of new materials and concepts for the PV devices is thus fundamental to reduce the overall production cost of PV technology and to increase their efficiency. Recent trends suggest that the development and successful utilization of nanomaterials could potentially lead to the realization of high efficient and low-cost solar cells. In this context, Single Wall Carbon Nanotubes (SWNTs) have been proposed as a promising material in organic $[2,3]$ and dye sensitized solar cells (DSSCs) [4-13]. However, as-produced SWNTs usually form entangled networks of bundles or ropes [14-17], due to van der Waals attraction forces along their length [18-21]. When in a bundle, SWNTs are far from their optimum mechanical, thermal, and optical properties [22-27]. Thus in order to fully exploit the technological potential of nanotubes for DSSCs, it is crucial to develop simple debundling techniques. Individualization/debundling of SWNTs is also crucial for the separation of SWNTs by chirality or between metallic ( $\mathrm{m}$ SWNTs) and semiconducting nanotubes (s-SWNTs), overcoming the limitations related to polydispersivity. SWNTs can be sorted by diameter [28-36], chirality [37-41], their metallic or semiconducting nature $[32,42-51]$, and length $[36,52,53]$.

Here we focus on the possible strategies to use enriched SWNTs in DSSCs, where they can serve multiple purposes such as: (1) transparent and conductor (TC) window at the photoanode, (2) charge transport, and (3) catalyst.

Indeed, enriched m-SWNTs can be used as TC films at the photoanode as well as catalyst at the counter electrode (cathode). For example, the conductivity of TC produced using highly enriched m-SWNTs can be enhanced by a factor of 6 in the visible spectrum with respect to unsorted material [54]. On the other hand, for the improvement of the DSSCs performance, m-SWNTs and/or chirality enriched sSWNTs with a suitable energy gap would facilitate electron transport from mesoscopic $\mathrm{TiO}_{2}$ particles to photoelectrode. Therefore, nanotubes enrichment is a vital step to improve the performances of nanotubes-based DSSCs. Here, we review the state of the art of the use of SWNTs in DSSCs.

\section{Structure and Mechanism of DSSCs}

DSSC is a new "type" of photoelectrochemical solar cell, used already by Becquerel for the discovery of the photovoltaic effect almost two century ago, which uses a liquid electrolyte as a charge transport medium [55]. The schematic representation of a DSSC is shown in Figure 1. A DSSC typically consists of a high porosity nanocrystalline photoanode made 
of a wide band gap semiconductor (usually the n-type semiconductor $\mathrm{TiO}_{2}$ with a bandgap of $3.2 \mathrm{eV}$ ) nanoparticles (15 to $20 \mathrm{~nm}$ diameter). The $\mathrm{TiO}_{2}$ nanoparticles are deposited on a transparent conducting oxide (TCO) glass supported and sensitized with a self-assembled monolayer of dye molecules anchored to the $\mathrm{TiO}_{2}$ surface [55]. The main difference, with respect to conventional cells, relies on the functional element responsible for light absorption (dye molecules), which is separated from the charge carrier transport itself [56]. The photoanode is immersed in an electrolyte solution containing a redox couple (iodide/iodine) and placed on a platinum counter electrode. Commonly, the platinum layer is deposited on transparent glass which is, in turn, coated by a conductive layer such as Indium Tin oxide (ITO) $[1,57]$.

The mechanism of a DSSC is listed schematically below [58]:

$$
\begin{gathered}
\mathrm{S}+\mathrm{h} v \longrightarrow \mathrm{S}^{*} \\
\mathrm{TiO}_{2} \longrightarrow \mathrm{S}^{+}+\mathrm{e}_{\mathrm{CB}}^{-}\left(\mathrm{TiO}_{2}\right), \\
\mathrm{S}^{*} \longrightarrow \mathrm{S} \\
\mathrm{S}^{+}+3 \mathrm{I}^{-} \longrightarrow 2 \mathrm{~S}+\mathrm{I}^{-3} \\
\mathrm{~S}^{+}+\mathrm{e}_{\mathrm{CB}}^{-}\left(\mathrm{TiO}_{2}\right) \longrightarrow \mathrm{S}+\mathrm{TiO}_{2}, \\
\mathrm{I}^{-3}+2 \mathrm{e}^{-}(\text {catalyst }) \longrightarrow 3 \mathrm{I}^{-}, \\
\mathrm{I}^{-3}+2 \mathrm{e}^{-}\left(\mathrm{TiO}_{2}\right) \longrightarrow 3 \mathrm{I}^{-}+\mathrm{TiO}_{2} .
\end{gathered}
$$

When illuminated, the dye molecules capture the incident photons (hv) generating electron/holes pairs (1a) [55]. The resultant electrons, at excited states $S^{*}$, which lie energetically above the conduction band (CB) edge of the $\mathrm{TiO}_{2}$, are quickly injected into the conduction band (CB) of the $\mathrm{TiO}_{2}$ (1b) and transported to the electron-collecting counter electrode, the cathode [55]. In this condition, the electron injection to the semiconductor (1b) can occur successfully, competing with the deactivation reaction (1c). Regeneration of dye molecules is accomplished by capturing electrons from a liquid electrolyte (iodide/iodine solution), sandwiched on the cathode, that catalyses the reduction of tri-iodide [55]. For efficient operation of the cell, the rate of electron injection must be faster than the decay of the dye-excited state [55]. Also, the oxidation of iodide (1d) and the reduction of iodine (1f) must effectively compete with the charge-separated state recombination reactions (1e) and (1g) that decrease the current production.

The most important electrochemical parameters for a solar cell are the open circuit voltage $\left(V_{\mathrm{OC}}\right)$, the maximum voltage under open circuit conditions, and the short circuit current $\left(I_{\mathrm{SC}}\right)$, that is, the maximum current when the cell is short circuited. Another key parameter of the solar cell is the fill factor (FF), defined as

$$
\mathrm{FF}=\frac{\left(V_{\max } \times I_{\max }\right)}{\left(V_{\mathrm{oc}} \times I_{\mathrm{sc}}\right)},
$$

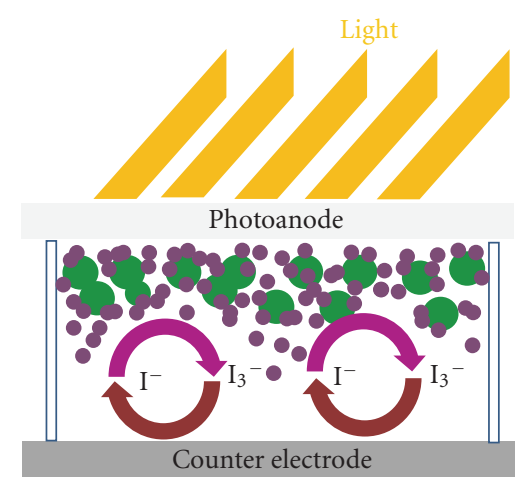

FIGURE 1: Schematic representation of the structure of a dye sensitized solar cell. The cell has 3 primary parts. On the top is a transparent photoanode made of Indium-doped tin oxide (ITO) deposited on the back of a transparent glass. On the back of the conductive plate is a layer of titanium dioxide $\left(\mathrm{TiO}_{2}\right)$, which forms into a highly porous structure with an extremely high surface area (green beads). A thin layer of a photosensitive rutheniumpolypyridinedye (purple beads) [55] is covalently bonded to the surface of the $\mathrm{TiO}_{2}$. A separate backing is made with a thin layer of the iodide electrolyte $\left(\mathrm{I}^{-} / \mathrm{I}_{3}^{-}\right)$spread over a conductive sheet, typically platinum metal (the counter electrode). The front and back parts are then joined and sealed together to prevent the electrolyte from leaking.

where $V_{\max }$ and $I_{\max }$ are the maximum voltage and current of the cell, respectively. The performance of a solar cell is determined by the energy conversion efficiency, $\eta$, defined ass

$$
\eta=\frac{P_{\max }}{P_{\text {inc }}}
$$

where $P_{\mathrm{MAX}}=I_{\mathrm{SC}} \times V_{\mathrm{OC}} \times \mathrm{FF}$ and $P_{\text {inc }}$ is the power incident light on the cell. On the other hand, the fraction of absorbed photons that is converted to electrical current defines the internal photocurrent efficiency (IPCE).

\section{Routes to Dispersion and Individualization of SWNTs}

The methods for debundling of SWNTs can be roughly classified in two major categories: covalent and noncovalent functionalization [59]. Significant research effort has been conducted in this field over the last 10 years [60-66]. Functionalization generally involves the creation of defect sites on SWNTs, where different functional groups can be attached. The ends of as-produced SWNTs can either be open or contain highly curved unstable fullerene-like end caps $[67,68]$. SWNT sidewalls also contain defects, generally in the form of pentagon and heptagon pairs, $\mathrm{sp}^{3}$ hybridized defects and vacancies in the lattice $[69,70]$. Strong oxidative treatments are used to remove the catalyst particles and to open additional defect sites on the SWNT sidewalls and end caps, resulting in carboxylic $(-\mathrm{COOH})$ functional groups at these locations $[62,71-74]$. Depending on the functional groups attached, stable SWNT dispersions in aqueous and organic solvents can be obtained [75]. However, this approach has certain disadvantages because of 
SDS

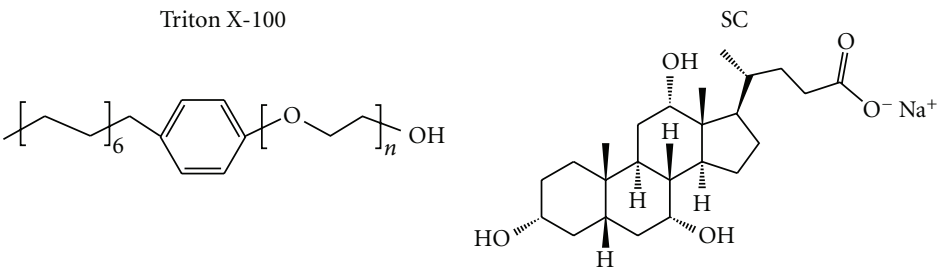

SDBS<smiles></smiles>

$\operatorname{DTAB}(n \sim 10)$

$\mathrm{CTAB}(n \sim 14)$<smiles>C[C@H](CCC(=O)O[NH3+])C1CC[C@H]2[C@H]3CC[C@H]4C[C@@H](O)CC[C@]4(C)[C@H]3C[C@H](O)[C@]12C</smiles>

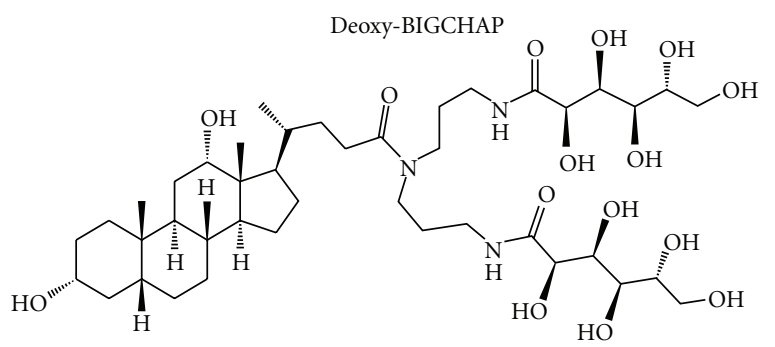<smiles>[NH3+]OC(=O)CCCc1ccc2ccc3cccc4ccc1c2c34</smiles>

Brij $78(n \sim 20)$

Brij $700(n \sim 100)$

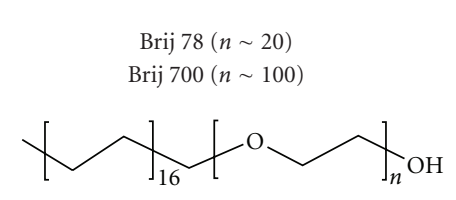

PVP<smiles>CC(C)(C)CC(N1CCCC1=O)C(C)(C)C</smiles>

TDC<smiles>C[C@H](CCC(=O)NCCS(=O)(=O)O[NH3+])[C@H]1CC[C@H]2[C@H]3CC[C@H]4C[C@@H](O)CC[C@]4(C)[C@H]3C[C@H](O)[C@@]21C</smiles>

CPL<smiles>CCCCCCCCCCCCCCCC[n+]1ccccc1Cl</smiles>

Igepal DM-970

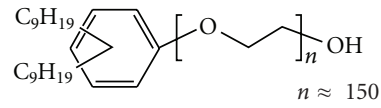<smiles>CC(C)(C)CC(c1ccc(S(=O)(=O)[OH2+])cc1)C(C)(C)C</smiles>

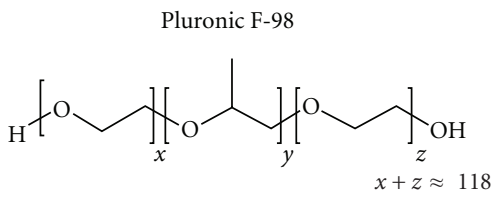

FIGURE 2: Chemical structures of some commonly used surfactants and polymers for SWNT dispersion in aqueous solutions. Abbreviations: SDS: sodium dodecyl sulfate; SDBS: sodium dodecylbenzenesulphonate; PVP: polyvinylpyrrolidone; Deoxy-BIGCHAP: N,N-bis(3-Gluconamidopropyl)deoxycholamide; SPB: Sodium Pyrenebutyrate; DTAB: dodecyltrimethylammonium bromide; CTAB: cetyltrimethylammonium bromide; CPL: Cetylpyridinium Chloride; NaPSS: sodium polystyrene sulphonate; SC: sodium cholate; SDC: sodium deoxycholate; TDC: sodium taurodeoxycholate.

the possible damage of SWNTs during the functionalization procedure, due to disruptions in their extended $\pi$-network, therefore preventing their use in many applications [76-80].

An alternative approach relies on the use of noncovalent interactions that relies on the physical adsorption of dispersant molecules on the SWNT sidewalls. This second method does not damage the nanotube surface and consists, in the addition of highly soluble dispersant agents [61$66,81]$ into solution. Adsorption of dispersant molecules is a nondestructive method to individualize SWNTs in aqueous solutions, inducing only small shifts $(<50 \mathrm{meV})$ in transition energies due to change in dielectric environment
[80]. Surfactants and deoxyribonucleic acid (DNA) are mostly used in aqueous SWNT dispersions while polymers, depending on their solubility, are used for both aqueous and organic solvent dispersions. Much effort has been devoted towards finding suitable molecules to interface the nonpolar sidewalls of SWNTs with water. To date, stable dispersions of pristine SWNTs in water $/ \mathrm{D}_{2} \mathrm{O}$ have been achieved with the aid of ionic and nonionic surfactants $[61,63,65]$, DNA [66, $82,83]$, water soluble polymers $[63-65,84]$, polypeptides [84-86] and cellulose derivatives [87]. The most common surfactants able to stably individualize SWNTs in water [61, 63,65 ] include Triton-X, Pluronic, Igepal, and Brij series on 


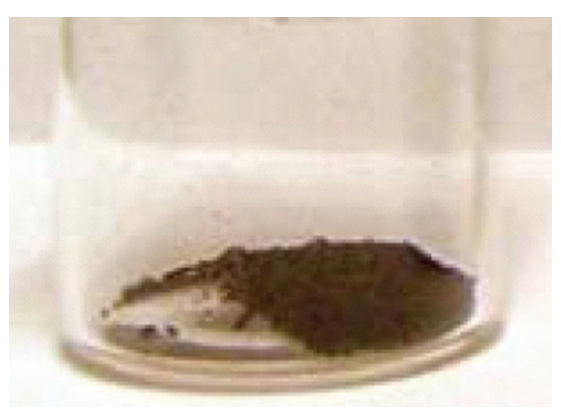

(a)

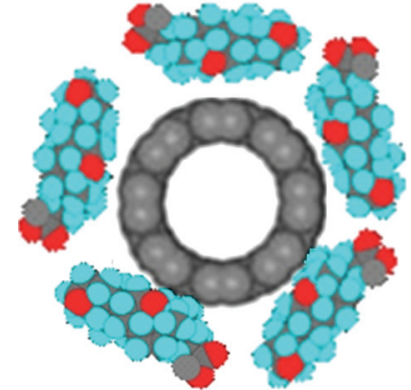

(c)

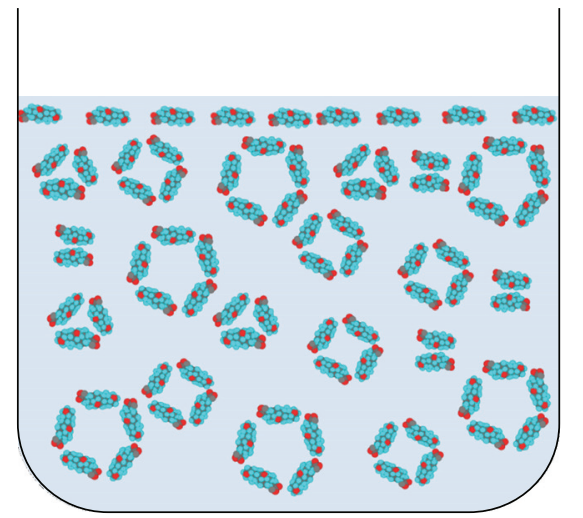

(b)

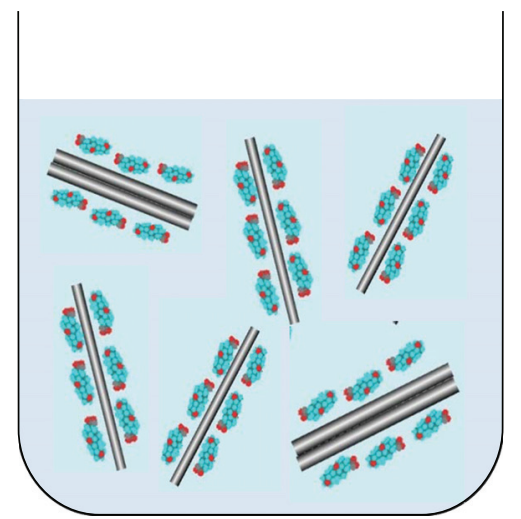

(d)

FIGURE 3: (Color) Schematics of SWNT dispersion mechanism in water by physical adsorption of dispersant molecules. (a) SWNTs powders. (b) Surfactant micelles formation in aqueous solution. The insertion of SWNTs in the surfactant aqueous solution and the ultrasonic treatment cause the wrapping of surfactants around SWNT sidewalls. The surfactants wrap with their nonpolar tail the SWNT sidewalls while extending their polar or ionic end in contact with aqueous solution. (c) Cross-sectional view of the possible arrangement of the SDC molecules around the SWNT sidewalls. (d) Final dispersion with individual and bundled SWNTs wrapped by surfactant molecules.

the nonionic side and sodium dodecyl sulfate (SDS), sodium dodecylbenzenesulphonate (SDBS), sodium cholate (SC), sodium deoxycholate (SDC), sodium taurodeoxycholate (TDC), dodecyltrimethylammonium bromide (DTAB), and cetyltrimethylammonium bromide (CTAB) on the ionic side (see Figure 2). When SWNTs are individualized by the shear forces from the formation and collapse of cavities generated by ultrasounds [88], surfactants wrap with their nonpolar tail the SWNT sidewalls while extending their polar or ionic end in contact with aqueous solution; see Figure 3. This process makes the SWNTs compatible with the aqueous medium and prevents their reaggregation [61, $63,65]$. Large SWNT bundles together with catalyst particles are removed via ultracentrifugation, leaving the supernatant enriched in small bundles and individually dispersed SWNTs [89]. Water-soluble polymers are reported to wrap around SWNTs $[64,90]$ facilitating their debundling. The wrapping of SWNTs by water-soluble polymers is thermodynamically favored by the removal of the hydrophobic interface between the SWNT sidewall and the aqueous medium [64, 90]. Cellulose derivatives were also employed as dispersants for SWNTs in water, resulting in high concentration of individual SWNTs. SWNTs can also be individualized in aqueous dispersions of Gum Arabic (GA), a highly branched arabinogalactan polysaccharide $[90,91]$. DNA is an excellent
SWNT dispersant in water [66, 82, 83]. Reference [66] proposed that single-stranded DNA (ss-DNA) forms a helical wrap around SWNT sidewalls by $\pi$-stacking. The authors showed that the binding free-energy of ss-DNA to SWNTs is higher than the energy between two SWNTs, facilitating the dispersion process [66]. Other biomolecules, such as polypeptides, are also efficient in dispersing SWNTs in water $[85,86]$. Reference [85] designed a peptide, called nano-1, which folds into an $\alpha$-helix. Its hydrophobic side interacts with the SWNT sidewalls whereas the hydrophilic side interacts with the aqueous medium. Carboxymethyl cellulose [87, 92] and hydroxyethyl cellulose [87] have also been reported to individualize SWNTs with higher loading compared to surfactants and polymers.

\section{Characterization of SWNT Dispersions}

Optical techniques to probe SWNTs are very advantageous from the experimental point of view. The measurements are nondestructive and can usually be carried out at room temperature under ambient pressure. Optical Absorption (OAS), Photoluminescence Excitation (PLE), and Raman spectroscopy are usually used for the characterization of the SWNT dispersions. These methods are employed to assess the concentration and presence of individual SWNTs or their 


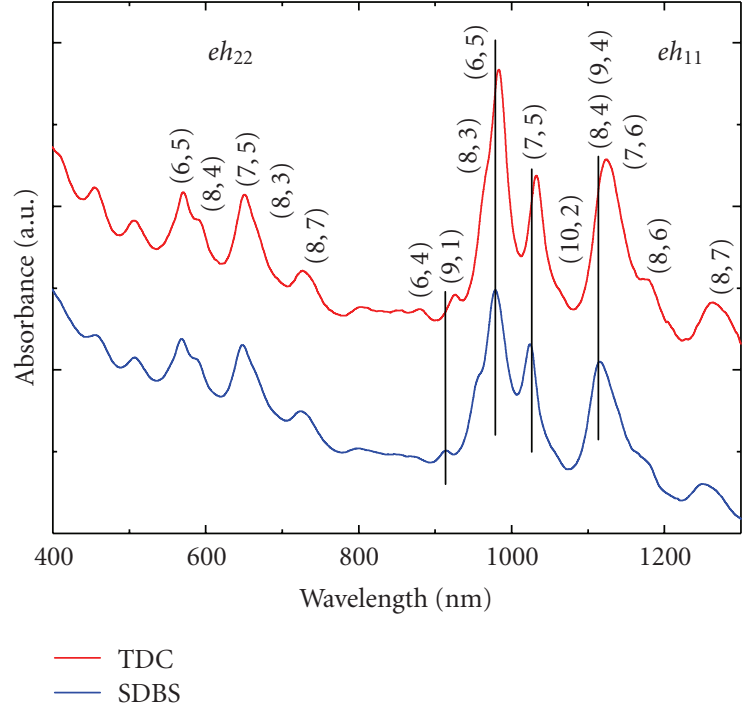

FIgure 4: Optical absorption spectrum of CoMoCAT SWNTs dispersed in DI water using TDC (red line) and SDBS (blue line) as surfactant. The absorption peaks from different SWNT species are assigned according to $[12,33]$. The shift in the peak positions and widths is due to different surfactants, which change the, dielectric environment. The vertical lines are intended to guide the eyes.

bundles and may be used as independent or complementary characterization tools [93-99].

4.1. Optical Absorption Spectroscopy. OAS of nanotube dispersions detects various properties of nanotubes, such as excitonic transition energy, bundle status, and nanotube loading in the dispersions $[100,101]$. In OAS, the broadening and red-shift of absorption peaks usually indicate the presence of SWNT bundles $[61,102]$. The excitonic transitions of SWNTs are also strongly modulated by different dielectric environments [65, 103-105]. Absorption spectra of CoMoCAT SWNTs dispersed in aqueous dispersion with the aid of different surfactants are presented in Figure 4. The spectra illustrate the shift in absorption peaks due to different dielectric environments surrounding the SWNTs.

4.2. Photoluminescence Excitation Spectroscopy. Compared to absorption spectra, PLE maps (see, Figure 5) offer richer details of the SWNT optical properties and of their interaction with the surrounding dielectric environment $[96,106$, 107]. Exciton-exciton resonances are the major features in PLE maps of SWNT dispersions. The $\left(e h_{i i}, e h_{11}\right)$ resonances ( $i=1,2, \ldots$, etc.) from different species of SWNTs appear as sharp features $\left(\lambda_{\mathrm{ex}}, \lambda_{\mathrm{em}}\right)$, where $\lambda_{\mathrm{ex}}$ and $\lambda_{\mathrm{em}}$ are the excitation and emission wavelengths, respectively. Other peaks detected in PLE maps are associated to excitonic phonon sidebands [108-110], excitonic energy transfer (EET) [106, 107, 111], or bright phonon sidebands (BSs) of dark K-momentum excitons [112]. EET occurs in bundles when the excitation of the $e h_{i i}$ of large bandgap donor SWNTs (d-SWNT) induces emission from the $e h_{11}$ of a smaller bandgap acceptor (aSWNT) $[106,107]$. EET can thus identify the presence of

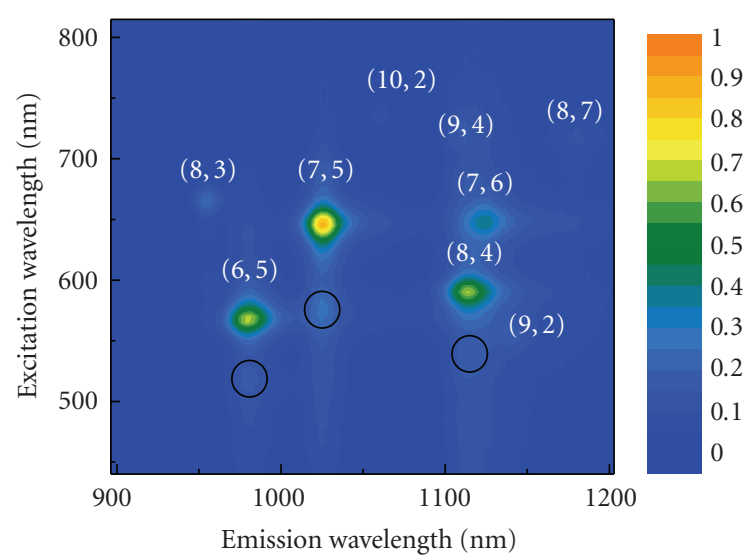

Figure 5: PLE map for SDBS-encapsulated CoMOCAT SWNT dispersion. Each $\left(e h_{22}, e h_{11}\right)$ resonance is labeled with the chiral index of the corresponding SWNT. Open circles indicate the positions of phonon sidebands $e h_{22}^{\text {ph }}$ of SWNTs. Broad and elongated spectral features are assigned to EET between s-SWNTs.

small bundles in dispersion [106, 107]. EET is also largely independent from perturbations induced by surrounding dielectric environments, since d- and a-SWNTs must be in the same bundle for EET to happen [106, 107, 113]. Indeed, the EET range is limited to a few nanometers and governed by the Förster resonance $[106,110,113]$. In general, the PL intensity does not directly reveal the relative abundance of SWNTs [114]. However, the relative PL intensity of different chiralities can be used to compare the effectiveness of their individualization.

4.3. Raman Spectroscopy. Raman spectroscopy is a fast, powerful, and nondestructive method for the characterization of carbon materials. A number of important informations, such as diameter, chirality, metallic or semiconducting nature, and orientation can be obtained from Raman characterization of SWNTs. The Raman spectra of SWNTs consist of a rich set of features.

The low-frequency features in the 120 to $350 \mathrm{~cm}^{-1}$ region for the usual SWNTs diameter range $(\sim 0.7-2 \mathrm{~nm})$ are the so-called radial breathing modes (RBMs) [99]. The RBM modes are unique in SWNTs and used to determine the diameter and chirality of SWNT samples [115-119]. RBM position $\operatorname{Pos}(R B M)$ is inversely related to SWNT diameter, $d$, $[115,116]$ by $\operatorname{Pos}(R B M)=C_{1} / d+C_{2}$. The combination of $\operatorname{Pos}(R B M)$ with the excitation wavelength and the "Kataura plot" [120], it is possible to derive the SWNT chirality [117119]. A variety of $C_{1}$ and $C_{2}$ have been proposed for this relation $[115-117,119]$.

Raman spectroscopy can also probe any possible damage during ultrasonic dispersions, by monitoring the evolution of the D peak [121-123]. Indeed, the D peak appears in materials in the presence of structural disorder [121-123]. It originates by a breathing mode of hexagonal rings and it is observed in the frequency region between 1200 and $1400 \mathrm{~cm}^{-1}$ [121-123]. 
The Raman spectrum of SWNTs, in the range 1500$1600 \mathrm{~cm}^{-1}$, is characterized by the presence of two distinct features so-called $\mathrm{G}^{+}$and $\mathrm{G}^{-}$bands. The origin of these two bands arises by the splitting of the double degenerate, Raman-active $E_{2 g}$ mode of graphene [124-127]. In s-SWNTs, they originate from the longitudinal (LO) and tangential (TO) modes [125]. The positions of the $\mathrm{G}^{+}$and $G$-peaks, $\operatorname{Pos}\left(G^{+}\right), \operatorname{Pos}\left(G^{-}\right)$, are diameter dependent and the separation between them decreases with increasing diameter [125]. In m-SWNTs, the assignment of the $\mathrm{G}^{+}$and $\mathrm{G}^{-}$bands is the opposite, and the full width at half maximum of the G-peak, $\operatorname{FWHM}\left(G^{-}\right)$, is larger while $\operatorname{Pos}\left(G^{-}\right)$is downshifted with respect to s-SWNTs [125]. Doping could also modify both the FWHMs and peaks' positions [128-130]. In s-SWNTs, doping upshifts $\operatorname{Pos}\left(G^{+}\right)$but does not influence $F W H M\left(G^{+}\right)$ $[128,129]$. In m-SWNTs, electron or hole doping causes $\operatorname{Pos}\left(G^{-}\right)$blueshift and $\operatorname{FWHM}\left(\mathrm{G}^{-}\right)$decrease $[128,129]$. Although a large number of excitation wavelengths are necessary for a complete characterization of SWNT samples $[119,131]$, useful information can be derived even with few excitations, in particular when Raman compares the same SWNTs dispersed in different solvents and/or surfactants or the final dispersion with the starting material.

\section{State of the Art in SWNT Separation/Enrichment}

Currently available SWNT synthesis methods yield nanotubes with uncontrolled diameter, chirality, and, consequently, optical properties. Postproduction enrichment is the more reliable route towards the separation/enrichment of SWNTs. Greater understanding of the dispersion mechanism, especially in aqueous environments, is crucial for the separation of SWNTs. This is because, well-established techniques for the separation of biological molecules, for example, conventional and density gradient ultracentrifugation [132], electrophoresis [133], and variations of chromatography [134] are the prime candidates for successful SWNT sorting.

Sorting of SWNTs in a liquid environment usually follows the strategy of "amplifying" their subtle differences in chemical reactivity by covalent and noncovalent functionalization $[59,60]$.

Methods based on electrophoresis and its variants were the first to be demonstrated for the sorting of SWNTs. In conventional methods of electrophoresis, nanotubes are sorted with respect to their relative mobility in gel [36, 49], capillary [30], or free-solution electrophoresis [46] in response to a direct $(\mathrm{dc})$ or alternating current $(\mathrm{ac})$ field [30, 36, 46, 49]. Ion exchange (IEC), column (CC), and size exclusion (SEC) chromatography may be used to sort SWNTs by length, electronic type, or diameter. Separation by diameter or $\mathrm{m}$ - versus s-SWNTs by chromatography is possible through wrapping with single-strand deoxyribonucleic acid (ss-DNA) [29, 37, 40]. Centrifugal force can be used to separate mixtures based on their density. In the case of SWNTs sorting, centrifugation can be performed in a constant, step, or linear density gradient medium. Conventional ultracentrifugation is carried out in a constant density medium, sorting SWNTs according to their sedimentation coefficient, which strongly depends on their molecular weight and shape [135]. Like IEC, SWNT sorting by the conventional ultracentrifugation method suffers from convolution among their diameter and length [135]. On the other hand, nanotube sorting is achieved by exploiting the buoyant density difference of surfactant-encapsulated individual tubes $[31-33,35]$. This results in a spatial separation inside an ultracentrifuge cell, overcoming the limitations of conventional ultracentrifugation in a constant density medium [35]. DGU allows also the separation of sand $\mathrm{m}$-SWNTs [32]. The $\mathrm{m}$ - versus s-SWNTs separation is achieved in a co-surfactants mixture, resulting in different buoyant densities between the two species. Recently, [136] demonstrated that nanotube individualization and uniform coverage by surfactant molecules are key parameters in the separation mechanism.

\section{SWNTs as Transparent Conductive Electrodes}

The different debundling and sorting strategies, discussed above, together with film fabrication methods have been employed in the investigation of SWNTs as a coating agent to form TCs, which are a crucial component both in solar cells [2] and many other optoelectronic devices, such as flatpanel displays $[137,138]$. The current choice of material for such applications is crystalline ITO, a doped n-type semiconductor, with transmittance $(\mathrm{T})$ higher than $80 \%$, coupled with sheet resistance $\left(R_{S}\right)$ as low as $10 \Omega / \square$ on glass $[57,139-141]$. ITO is the most expensive components of a DSSC [13]. However, other than the cost, there are other problems related to the use of ITO. Indeed, ITO requires deposition at high temperature, hindering the deposition on some substrates (e.g., polymeric substrates). Another disadvantage is related to the reduced conductivity of large area electrodes $\left(\sim 10 \mathrm{~cm}^{2}\right)$. Moreover, the brittleness of ITO limits its use in applications where flexibility is required. Thus far, other metal oxides [142], thin metal films [143-145], metal grids [146] and carbonaceous materials such as graphene and carbon nanotube (CNT) have been investigated for ITO replacement. In particular, CNT networks and composites have several advantages with respect to commercially available TCs. Indeed, SWNTs have high $\mathrm{T}$ in the visible and infrared region coupled with high environmental stability and flexibility [147]. SWNTs are generally inert to bases, humidity, and high temperatures. Finally, SWNT films can be fabricated at low cost. Reference [147] reported a TC film of pure SWNTs. The SWNTs network, produced by vacuum filtration of a surfactant-assisted dispersion of SWNTs followed by a transfer printing process, showed $R_{s}$ of $\sim 30 \Omega / \square$ coupled with $\mathrm{T}>70 \%$ in the visible region and $>90 \%$ in the near IR. In [148] an acid treatment was introduced in order to remove the surfactant from the flexible film produced by vacuum filtration and deposited on PET. Reference [149] presented an acid treatment of the filtered films in order to improve conductivity via stable postdeposition functionalization. Reference [150] demonstrated that transport in SWNT networks is dominated by resistance at network junctions. In the same work it is also demonstrated that acid 
treatment reduces junction resistances whereas annealing significantly increases this resistance [150]. A different transfer technique, exploiting a polydimethysiloxane (PDMS) stamp, was introduced in [151]. The method combines a PDMS-based transfer-printing technique with vacuum filtration, and allows controlled deposition and patterning of highly conducting SWNT films [151]. Reference [152] also demonstrated the application of such patternable films in electrochromic devices. Many aspects related to SWNT films for transparent and plastic electronics, such as properties and fabrication technologies are reviewed in [153]. Reference [154] investigated $R_{s}$ as a function of nanotube network density showing 2D percolation behaviour. Spin coating and rod coating of the SWNT dispersions are used as alternatives to the vacuum filtration technique for the fabrication of TC films $[155,156]$. A T of about $80 \%$ coupled with $R_{s}$ of $85 \Omega / \square$ was shown by a SWNT film spin coated on PET from an initial dispersion in dichloroethane (DCE) [155]. Recently, [156] reported the fabrication of SWNT films by draw-down rod coating of purified HiPco SWNTs dispersed in water at high concentration with the aid of surfactants [156]. The authors investigated the influence of surfactants on the rheological behaviour for coating and drying [156]. Doping by fuming sulfuric acid yielded the films with $R_{s}$ as low as 80 and $140 \Omega / \square$ coupled with T of $70 \%$ and $80 \%$, respectively [156]. SWNT dispersions in aqueous solution or organic solvents were also investigated for the development of TC polymernanotube composites. The most promising route involves the use of conductive polymers as matrix [157-160]. Reference [157] via a vacuum filtration of an aqueous dispersions of poly(3,4-ethylenedioxythiophene):poly(styrene sulfonate) (PEDOT:PSS) and SDS/SWNTs produced composites with $R_{s}$ of $80 \Omega / \square$ and $\mathrm{T}$ of $75 \%$ (at $550 \mathrm{~nm}$ ). Functionalized SWNTs, dispersed either in water [158] or in organic solvents [159], embedded in PEDOT:PSS matrix have also been investigated. Another conductive polymer investigated to date is P3HT. Composites produced by drop casting of a CNT-P3HT dispersion in chloroform are reported in [160] However, in the case of P3HT, high conductivity is limited by the oxidation of polymer itself, which requires a reduction treatment in hydrazine. Non conductive polymer matrix has been also employed in SWNT-PE (polyethylene) composites, produced by nanotube infiltration $\left(R_{s}\right.$ of $50 \mathrm{k} \Omega / \square$ with optical transparency of 80\%) [161]. Layer-by-layer assembly of Polyvinyl-Alcohol (PVA) and SWNT/PSS composite [162] shows lower conductivities $\left(10^{2}-10^{3} \mathrm{~S} / \mathrm{m}\right.$ at room temperature) compared to pure CNT films $\left(10^{4}-10^{6} \mathrm{~S} / \mathrm{m}\right)$, but higher than most of other PVA-SWNT or polymer-SWNT composites $[163,164]$.

Figure 6 summarizes the best results reported thus for SWNTs-based TCs. The performances of SWNTs-based TCs are compared with those of ITO and other materials. Although the performances of SWNTs-based TCs are slightly lower with respect to ITO or graphene produced by chemical vapour deposition (CVD) [165], they compare favourably with graphene films produced by liquid phase exfoliation [166]. However, the use of sorted m-SWNTs at the TCs in DSSCs can boost the efficiency of SWNTs-based DSSCs. Indeed, [54] demonstrated an increase in conductivity of TCs

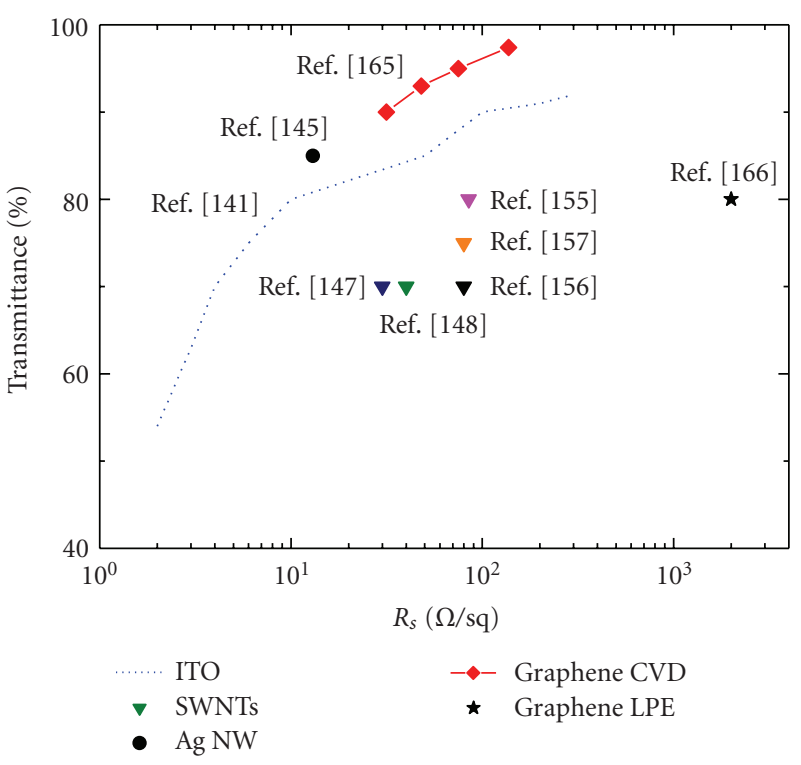

Figure 6: $T$ versus $R_{s}$ spectrum for different TCs. Legend: dotted line: ITO; red rhombuses: CVD graphene; black star: vacuum filtration of liquid phase-exfoliated (LPE) graphene; black dot: silver nanowires; triangles: SWNT films.

by using predominantly enriched $\mathrm{m}$-SWNTs. The films were produced by vacuum filtration of sorted SWNT by DGU and showed $R_{s}$ of $231 \Omega / \square$ with $75 \% \mathrm{~T}$ in the visible, compared to $R_{s}$ of $1340 \Omega / \square$ for the unsorted material [54].

\section{SWNTs as Counter-Electrodes in Dye Sensitized Solar Cells}

The use of SWNTs at the counter electrode of DSSCs is attractive for several reasons. Regeneration of dye molecules is accomplished by capturing electrons from a liquid electrolyte (iodide/iodine solution), sandwiched on the counter electrode, which catalyses the reduction of tri-iodide [55]. Another important function of the counter electrode relies in the back transfer the electrons arriving from the external circuit to the redox system. The most important requirements for the counter electrode material are a high exchange current density and a low charge-transfer resistance [167].

Currently, DSSCs cathodes are made of Platinum $(\mathrm{Pt})$ layers deposited on transparent glass which are, in turn, coated by a TC such as ITO [1]. Glass is brittle and has shape limitations while $\mathrm{Pt}$ is a rare and expensive material. Furthermore Pt tends to degrade over time when in contact with an iodide/iodine liquid electrolyte, reducing the overall efficiency of DSSCs [168]. During the last years strong efforts have been directed towards the replacement of such elements with low-cost and more versatile materials. Carbonaceous materials feature good catalytic properties, electronic conductivity, corrosion resistance towards iodine, high reactivity, abundance, and low cost [169]. In 1996 [170] demonstrated the importance of the high surface area introducing carbon black powder in graphite counter electrodes to enhance its catalytic activity. Since then, 
other research groups have employed different carbonaceous materials such as: carbon black, activated carbon, graphite, CNTs, and recently graphene [4-9]. In particular, SWNTs combine advantages such as high electrical conductivity, chemical stability, and high surface area with good electrochemistry and catalytic properties making them suitable for applications in many energy conversion technologies such as counter electrode in DSSCs [171]. Moreover, SWNTs are efficient to catalyze the tri-iodide reduction and, thus, are good candidates to replace Platinum in DSSCs.

For example, SWNTs have a higher surface area with respect to multi wall CNTs (MWCNT) that have been investigated as counter electrode in DSSCs, achieving higher efficiency and longer stability with respect to Pt-sputtered counter electrode [168].

Reference [9] demonstrated that ozone-treated SWNTs films increases their catalytic activity due to the introduction of defects. In this view functionalized SWNTs could also be another option for application in counter electrodes. Metal sheets or foils are flexible substrates with excellent electrical and thermal conductivities [172]. Recently, [13] demonstrated the preparation of DSSC based on a novel stainless steel cathode coated with commercial low-cost nonpurified SWNTs. The authors achieved an overall solar energy conversion efficiency of $3.92 \%$, which was higher than that obtained with Pt-transparent/FTO counter electrodes [13].

Enrichment of smaller diameter m-SWNTs may be useful for the improvement of the performance of the counter electrode in DSSCs. Indeed, considering that the chemical reactivity of a material is strongly related to the surface areato-volume ratio, very small diameter SWNTs react faster than very large diameter SWNTs or MWNTs. Moreover, the use of high conductive $\mathrm{m}$-SWNTs would improve the rate transfer of the electrons arriving from the external circuit to the redox system. A sorting strategy that involves a length separation followed by a diameter sorting of m-enriched SWNTs would produce long and small diameter $\mathrm{m}$-SWNTs that are the ideal material for the fabrication of the counter electrode. Indeed, the use of long tubes should reduce the intertube connections increasing the conductivity of the film. The optimization of conductivity and catalytic activity of SWNTs films makes them ideal material to replace simultaneously both platinum and TC in DSSCs opening the way for inexpensive roll-to-roll processing.

\section{Incorporation of SWNTs in $\mathrm{TiO}_{2}$ Electrode}

Electron transfer from the adsorbed dyes to the $\mathrm{TiO}_{2}$ electrode, the suppression of charge recombination between the injected electrons and the oxidized dye, together with an efficient hole transport to the counter electrode are investigated strategies to enhance the performance of DSSCs. In this context, considerable efforts have been made to improve the cell performance by modifying $\mathrm{TiO}_{2}$ electrodes using CNTs [12, 173, 174]. Reference [174] fabricated a DSSC using $\mathrm{TiO}_{2}$-coated MWNTs, produced by Sol-Gel method, achieving an increase of 50\% in conversion efficiency with respect to conventional DSSC, attributed to the increase in short circuit current density $\left(\mathrm{J}_{\mathrm{sc}}\right)$. Recently, [12] reported the use of an SWNT network as scaffolds of dye-sensitized $\mathrm{TiO}_{2}$ particles to promote charge transport in mesoscopic semiconductor films. The authors demonstrated that the SWNT network in the film has no noticeable influence on the charge injection process from the excited $\mathrm{Ru}(\mathrm{II})$ trisbipyridyl complex into $\mathrm{TiO}_{2}$ particles [12]. However, SWNT network plays an important role in improving the charge separation, as the rate of back electron transfer between the oxidized sensitizer $(\mathrm{Ru}(\mathrm{III}))$ and the injected electrons becomes slower in the presence of the SWNTs scaffold [12]. DSSCs with SWNTs used as scaffold show an improvement in the photocurrent generation that is neutralized by a lower photovoltage [12]. Indeed, the apparent Fermi level of the $\mathrm{TiO}_{2}$ and SWNT composite becomes more positive than that of pristine $\mathrm{TiO}_{2}$ [12]. However, the efficiency of the DSSC employing the ITO/SWNT/TiO $/ 2 / \mathrm{Ru}(\mathrm{II})$ electrode $(0.13 \%)$ was smaller than that with the $\mathrm{ITO}_{\mathrm{TiO}} / \mathrm{Ru}(\mathrm{II})$ electrode $(0.18 \%)$ [12]. This decrease was attributed to the reduction of the $\mathrm{V}_{\mathrm{oc}}$ by about $60 \mathrm{mV}$ [12]. Recently, [175] incorporated graphene into $\mathrm{TiO}_{2}$ nanostructure photoanode to form graphene bridges in DSSCs, demonstrating that graphene can enhance the charge transport rate, preventing the charge recombination and increasing the light collection efficiency. Moreover, the efficiency is improved as well [175]. The authors also pointed out that SWNTs suffer some disadvantages with respect to graphene, essentially related to the one-dimensional structure that hinders a good contact with the $\mathrm{TiO}_{2}$ nanoparticles [175]. Moreover, the work function of SWNTs was calculated and experimentally measured to be higher than MWNTs [176] and graphene [175]. This hinders the electron transport to the photoanode. However, it has been shown that the work function is diameter dependent, increasing with reduction of diameter [176]. In order to increase the performance of the DSSCs, it is highly desirable to use large diameter m-SWNTs or sSWNTs with a suitable position of conduction band that would facilitate electron transport from mesoscopic $\mathrm{TiO}_{2}$ particles to ITO electrode through the SWNTs.

\section{Conclusions and Perspective}

In this paper, we reviewed the state of the art concerning debundling and sorting of SWNTs, fundamental for many of nanotube-based applications. Further, some of the recent progresses on the application of SWNTs in DSSCs have been summarized. The use of enriched m-SWNTs generally improves the conductivity of transparent films compared with unsorted material. In the near future, the enrichment of metallic SWNTs with a defined diameter could permit the fabrication of transparent conductive coatings with tunable optical transmittance. The use of SWNTs as counter electrode opens up new industrial opportunities for large area, long-term stability, and low- cost DSSCs. In particular, a length separation followed by a diameter sorting of m-enriched SWNTs yields long and small diameter $\mathrm{m}-\mathrm{SWNT}$. This is the ideal material for the fabrication of the counter electrode as long tubes should improve the conductivity of the cathode. At the same time small diameter tubes enhance the chemical reactivity. The excellent 
electron transfer behaviour and the one-dimensional nature of SWNTs render them useful for the suppression of charge recombination between the injected electrons and the oxidized dye. Thus, nanotubes sorting is the ideal route to improve the performance of nanotube-based DSSCs.

\section{Acknowledgments}

The author acknowledges A. C. Ferrari, T. Hasan, G. Privitera, F. Torrisi, S. S. Awan, P. H. Tan, and G. Calogero for stimulating discussions and funding from the Newton International Fellowship.

\section{References}

[1] C. G. Granqvist, "Transparent conductors as solar energy materials: a panoramic review," Solar Energy Materials and Solar Cells, vol. 91, no. 17, pp. 1529-1598, 2007.

[2] J. van de Lagemaat, T. M. Barnes, G. Rumbles, et al., "Organic solar cells with carbon nanotubes replacing $\mathrm{In}_{2} \mathrm{O}_{3}$ : $\mathrm{Sn}$ as the transparent electrode," Applied Physics Letters, vol. 88, no. 23, Article ID 233503, 2006.

[3] S. Bhattacharyya, E. Kymakis, and G. A. J. Amaratunga, "Photovoltaic properties of dye functionalized single-wall carbon nanotube/conjugated polymer devices," Chemistry of Materials, vol. 16, no. 23, pp. 4819-4823, 2004.

[4] T. N. Murakami, S. Ito, Q. Wang, et al., "Highly efficient dye-sensitized solar cells based on carbon black counter electrodes," Journal of the Electrochemical Society, vol. 153, no. 12, pp. A2255-A2261, 2006.

[5] K. Imoto, K. Takahashi, T. Yamaguchi, T. Komura, J.I. Nakamura, and K. Murata, "High-performance carbon counter electrode for dye-sensitized solar cells," Solar Energy Materials and Solar Cells, vol. 79, no. 4, pp. 459-469, 2003.

[6] Z. Huang, X. Liu, K. Li, et al., "Application of carbon materials as counter electrodes of dye-sensitized solar cells," Electrochemistry Communications, vol. 9, no. 4, pp. 596-598, 2007.

[7] K. X. Li, Z. X. Yu, Y. H. Luo, D. M. Li, and Q. B. Meng, "Review of recent progress in solid-state dye-sensitized solar cells," Journal of Materials Sciences and Technology, vol. 23, pp. 577-573, 2007.

[8] K. Suzuki, M. Yamaguchi, M. Kumagai, and S. Yanagida, "Application of carbon nanotubes to counter electrodes of dye-sensitized solar cells," Chemistry Letters, vol. 32, no. 1, pp. 28-29, 2003.

[9] J. E. Trancik, S. C. Barton, and J. Hone, "Transparent and catalytic carbon nanotube films," Nano Letters, vol. 8, no. 4, pp. 982-987, 2008.

[10] T. Hino, Y. Ogawa, and N. Kuramoto, "Preparation of functionalized and non-functionalized fullerene thin films on ITO glasses and the application to a counter electrode in a dye-sensitized solar cell," Carbon, vol. 44, no. 5, pp. 880-887, 2006.

[11] A. Kongkanand, R. M. Dominguez, and P. V. Kamat, "Single wall carbon nanotube scaffolds for photoelectrochemical solar cells. Capture and transport of photogenerated electrons," Nano Letters, vol. 7, no. 3, pp. 676-680, 2007.

[12] P. Brown, K. Takechi, and P. V. Kamat, "Single-walled carbon nanotube scaffolds for dye-sensitized solar cells," Journal of Physical Chemistry C, vol. 112, no. 12, pp. 4776-4782, 2008.

[13] G. Calogero, F. Bonaccorso, O. M. Maragò, P. G. Gucciardi, and G. Di Marco, "Single wall carbon nanotubes deposited on stainless steel sheet substrates as novel counter electrodes for ruthenium polypyridine based dye sensitized solar cells," Dalton Transaction, vol. 39, pp. 2903-2909, 2010.

[14] J. Tersoff and R. S. Ruoff, "Structural properties of a carbonnanotube crystal," Physical Review Letters, vol. 73, no. 5, pp. 676-679, 1994.

[15] A. Thess, R. Lee, P. Nikolaev, et al., "Crystalline ropes of metallic carbon nanotubes," Science, vol. 273, no. 5274, pp. 483-487, 1996.

[16] C. Journet, W. K. Maser, P. Bernier, et al., "Large-scale production of single-walled carbon nanotubes by the electric-arc technique," Nature, vol. 388, no. 6644, pp. 756-758, 1997.

[17] J. P. Lu, "Elastic properties of carbon nanotubes and nanoropes," Physics Review Letters, vol. 79, pp. 1297-1300, 1997.

[18] T. Hertel, R. E. Walkup, and P. Avouris, "Deformation of carbon nanotubes by surface van der Waals forces," Physical Review B, vol. 58, no. 20, pp. 13870-13873, 1998.

[19] J.-P. Salvetat, G. A. D. Briggs, J.-M. Bonard, et al., "Elastic and shear moduli of single-walled carbon nanotube ropes," Physical Review Letters, vol. 82, no. 5, pp. 944-947, 1999.

[20] L. A. Girifalco, M. Hodak, and R. S. Lee, "Carbon nanotubes, buckyballs, ropes, and a universal graphitic potential," Physical Review B, vol. 62, no. 19, pp. 13104-13110, 2000.

[21] M. J. López, A. Rubio, J. A. Alonso, L.-C. Qin, and S. Iijima, "Novel polygonized single-wall carbon nanotube bundles," Physical Review Letters, vol. 86, no. 14, pp. 3056-3059, 2001.

[22] A. B. Dalton, S. Collins, E. Muñoz, et al., "Super-tough carbon-nanotube fibres," Nature, vol. 423, no. 6941, p. 703, 2003.

[23] J. N. Coleman, U. Khan, and Y. K. Gun'ko, "Mechanical reinforcement of polymers using carbon nanotubes," Advanced Materials, vol. 18, no. 6, pp. 689-706, 2006.

[24] S. Berber, Y.-K. Kwon, and D. Tománek, "Unusually high thermal conductivity of carbon nanotubes," Physical Review Letters, vol. 84, no. 20, pp. 4613-4616, 2000.

[25] J.-C. Charlier, P. H. Lambin, and T. W. Ebbesen, "Electronic properties of carbon nanotubes with polygonized cross sections," Physical Review B, vol. 54, no. 12, pp. R8377R8380, 1996.

[26] Y.-K. Kwon, S. Saito, and D. Tománek, "Effect of intertube coupling on the electronic structure of carbon nanotube ropes," Physical Review B, vol. 58, no. 20, pp. R13314R13317, 1998.

[27] Y.-L. Li, I. A. Kinloch, and A. H. Windle, "Direct spinning of carbon nanotube fibers from chemical vapor deposition synthesis," Science, vol. 304, no. 5668, pp. 276-278, 2004.

[28] M. Zheng, A. Jagota, M. S. Strano, et al., "Structurebased carbon nanotube sorting by sequence-dependent DNA assembly," Science, vol. 302, no. 5650, pp. 1545-1548, 2003.

[29] M. S. Strano, M. Zheng, A. Jagota, et al., "Understanding the nature of the DNA-assisted separation of single-walled carbon nanotubes using fluorescence and raman spectroscopy," Nano Letters, vol. 4, no. 4, pp. 543-550, 2004.

[30] S. K. Doorn, M. S. Strano, M. J. O’Connell, et al., “Capillary electrophoresis separations of bundled and individual carbon nanotubes," Journal of Physical Chemistry B, vol. 107, no. 25, pp. 6063-6069, 2003.

[31] M. S. Arnold, S. I. Stupp, and M. C. Hersam, "Enrichment of single-walled carbon nanotubes by diameter in density gradients," Nano Letters, vol. 5, no. 4, pp. 713-718, 2005.

[32] M. S. Arnold, A. A. Green, J. F. Hulvat, S. I. Stupp, and M. C. Hersam, "Sorting carbon nanotubes by electronic structure 
using density differentiation," Nature Nanotechnology, vol. 1, no. 1, pp. 60-65, 2006.

[33] J. Crochet, M. Clemens, and T. Hertel, "Quantum yield heterogeneities of aqueous single-wall carbon nanotube suspensions," Journal of the American Chemical Society, vol. 129, no. 26, pp. 8058-8059, 2007.

[34] F. Hennrich, K. Arnold, S. Lebedkin, A. Quintillá, W. Wenzel, and M. M. Kappes, "Diameter sorting of carbon nanotubes by gradient centrifugation: role of endohedral water," Physica Status Solidi B, vol. 244, no. 11, pp. 3896-3900, 2007.

[35] N. Nair, W.-J. Kim, R. D. Braatz, and M. S. Strano, "Dynamics of surfactant-suspended single-walled carbon nanotubes in a centrifugal field," Langmuir, vol. 24, no. 5, pp. 1790-1795, 2008.

[36] D. A. Heller, R. M. Mayrhofer, S. Baik, Y. V. Grinkova, M. L. Usrey, and M. S. Strano, "Concomitant length and diameter separation of single-walled carbon nanotubes," Journal of the American Chemical Society, vol. 126, no. 44, pp. 1456714573, 2004.

[37] M. Zheng and E. D. Semke, "Enrichment of single chirality carbon nanotubes," Journal of the American Chemical Society, vol. 129, no. 19, pp. 6084-6085, 2007.

[38] S.-Y. Ju, J. Doll, I. Sharma, and F. Papadimitrakopoulos, "Selection of carbon nanotubes with specific chiralities using helical assemblies of flavin mononucleotide," Nature Nanotechnology, vol. 3, no. 6, pp. 356-362, 2008.

[39] S. N. Kim, Z. Kuang, J. G. Grote, B. L. Farmer, and R. R. Naik, "Enrichment of $(6,5)$ single wall carbon nanotubes using genomic DNA," Nano Letters, vol. 8, no. 12, pp. 4415-4420, 2008.

[40] X. Tu, S. Manohar, A. Jagota, and M. Zheng, "DNA sequence motifs for structure-specific recognition and separation of carbon nanotubes," Nature, vol. 460, pp. 250-253, 2009.

[41] A. Nish, J.-Y. Hwang, J. Doig, and R. J. Nicholas, "Highly selective dispersion of single-walled carbon nanotubes using aromatic polymers," Nature Nanotechnology, vol. 2, no. 10, pp. 640-646, 2007.

[42] R. Krupke, F. Hennrich, H. V. Lohneysen, and M. M. Kappes, "Separation of metallic from semiconducting single-walled carbon nanotubes," Science, vol. 301, no. 5631, pp. 344-347, 2003.

[43] R. Krupke, F. Hennrich, H. B. Weber, M. M. Kappes, and H. V. Lohneysen, "Simultaneous deposition of metallic bundles of single-walled carbon nanotubes using acdielectrophoresis," Nano Letters, vol. 3, no. 8, pp. 1019-1023, 2003.

[44] R. Krupke, F. Hennrich, M. M. Kappes, and H. V. Lohneysen, "Surface conductance induced dielectrophoresis of semiconducting single-walled carbon nanotubes," Nano Letters, vol. 4, no. 8, pp. 1395-1399, 2004.

[45] R. Krupke, S. Linden, M. Rapp, and F. Hennrich, "Thin films of metallic carbon nanotubes prepared by dielectrophoresis," Advanced Materials, vol. 18, no. 11, pp. 1468-1470, 2006.

[46] W.-J. Kim, M. L. Usrey, and M. S. Strano, "Selective functionalization and free solution electrophoresis of singlewalled carbon nanotubes: separate enrichment of metallic and semiconducting SWNT," Chemistry of Materials, vol. 19, no. 7, pp. 1571-1576, 2007.

[47] T. Tanaka, H. Jin, Y. Miyata, et al., "Simple and Scalable GelBased Separation of Metallic and Semiconducting Carbon Nanotubes," Nano Letters, vol. 9, p. 1497, 2009.

[48] K. Yanagi, Y. Miyata, and H. Kataura, "Optical and conductive characteristics of metallic single-wall carbon nanotubes with three basic colors; cyan, magenta, and yellow," Applied Physics Express, vol. 1, no. 3, Article ID 034003, 2008.

[49] T. Tanaka, H. Jin, Y. Miyata, and H. Kataura, "Highyield separation of metallic and semiconducting single-wall carbon nanotubes by agarose gel electrophoresis," Applied Physics Express, vol. 1, no. 11, pp. 1140011-1140013, 2008.

[50] K. Yanagi, T. Iitsuka, S. Fuj II, and H. Kataura, "Separations of metallic and semiconducting carbon nanotubes by using sucrose as a gradient medium," Journal of Physical Chemistry C, vol. 112, no. 48, pp. 18889-18894, 2008.

[51] K. Moshammer, F. Hennrich, and M. M. Kappes, "Selective suspension in aqueous sodium dodecyl sulfate according to electronic structure type allows simple separation of metallic from semiconducting single-walled carbon nanotubes," Nano Research, vol. 2, pp. 599-606, 2009.

[52] G. S. Duesberg, J. Muster, V. Krstic, M. Burghard, and S. Roth, "Chromatographic size separation of single-wall carbon nanotubes," Applied Physics A, vol. 67, no. 1, pp. 117119, 1998.

[53] K. Arnold, F. Hennrich, R. Krupke, S. Lebedkin, and M. M. Kappes, "Length separation studies of single walled carbon nanotube dispersions," Physica Status Solidi B, vol. 243, no. 13, pp. 3073-3076, 2006.

[54] A. A. Green and M. C. Hersam, "Colored semitransparent conductive coatings consisting of monodisperse metallic single-walled carbon nanotubes," Nano Letters, vol. 8, no. 5, pp. 1417-1422, 2008.

[55] B. O’Regan and M. Gratzel, "A low-cost, high-efficiency solar cell based on dye-sensitized colloidal $\mathrm{TiO}_{2}$ films," Nature, vol. 353, no. 6346, pp. 737-740, 1991.

[56] A. Goetzberger, C. Hebling, and H.-W. Schock, "Photovoltaic materials, history, status and outlook," Materials Science and Engineering R, vol. 40, no. 1, 2003.

[57] T. Minami, "Transparent conducting oxide semiconductors for transparent electrodes," Semiconductor Science and Technology, vol. 20, no. 4, pp. S35-S44, 2005.

[58] G. Calogero and G. D. Marco, "Red Sicilian orange and purple eggplant fruits as natural sensitizers for dye-sensitized solar cells," Solar Energy Materials and Solar Cells, vol. 92, no. 11, pp. 1341-1346, 2008.

[59] S. Niyogi, M. A. Hamon, H. Hu, et al., "Chemistry of singlewalled carbon nanotubes," Accounts of Chemical Research, vol. 35, no. 12, pp. 1105-1113, 2002.

[60] T. Hasan, Z. Sun, F. Wang, et al., "Nanotubes-Polymer Composites for Ultrafast Photonics," Advanced Materials, vol. 21, p. 3874, 2005.

[61] M. J. O'Connell, S. H. Bachilo, C. B. Huffman, et al., "Band gap fluorescence from individual single-walled carbon nanotubes," Science, vol. 297, no. 5581, pp. 593-596, 2002.

[62] J. Liu, A. G. Rinzler, H. Dai, et al., "Fullerene pipes," Science, vol. 280, no. 5367, pp. 1253-1256, 1998.

[63] M. F. Islam, E. Rojas, D. M. Bergey, A. T. Johnson, and A. G. Yodh, "High weight fraction surfactant solubilization of single-wall carbon nanotubes in water," Nano Letters, vol. 3, no. 2, pp. 269-273, 2003.

[64] M. J. O'Connell, P. Boul, L. M. Ericson, et al., "Reversible water-solubilization of single-walled carbon nanotubes by polymer wrapping," Chemical Physics Letters, vol. 342, no. 34, pp. 265-271, 2001.

[65] V. C. Moore, M. S. Strano, E. H. Haroz, et al., "Individually suspended single-walled carbon nanotubes in various surfactants," Nano Letters, vol. 3, no. 10, pp. 1379-1382, 2003. 
[66] M. Zheng, A. Jagota, E. D. Semke, et al., "DNA-assisted dispersion and separation of carbon nanotubes," Nature Materials, vol. 2, no. 5, pp. 338-342, 2003.

[67] M. A. Hamon, H. Hu, P. Bhowmik, et al., "End-group and defect analysis of soluble single-walled carbon nanotubes," Chemical Physics Letters, vol. 347, no. 1-3, pp. 8-12, 2001.

[68] S. Niyogi, M. A. Hamon, H. Hu, et al., "Chemistry of singlewalled carbon nanotubes," Accounts of Chemical Research, vol. 35, no. 12, pp. 1105-1113, 2002.

[69] A. Hirsch, "Functionalization of single-walled carbon nanotubes," Angewandte Chemie: International Edition, vol. 41, no. 11, pp. 1853-1859, 2002.

[70] S. Banerjee, T. Hemraj-Benny, and S. S. Wong, "Covalent surface chemistry of single-walled carbon nanotubes," Advanced Materials, vol. 17, no. 1, pp. 17-29, 2005.

[71] J. Chen, A. M. Rao, S. Lyuksyutov, et al., "Dissolution of fulllength single-walled carbon nanotubes," Journal of Physical Chemistry B, vol. 105, no. 13, pp. 2525-2528, 2001.

[72] M. A. Hamon, J. Chen, H. Hu, et al., "Dissolution of singlewalled carbon nanotubes," Advanced Materials, vol. 11, no. 10, pp. 834-840, 1999.

[73] N. I. Kovtyukhova, T. E. Mallouk, L. Pan, and E. C. Dickey, "Individual single-walled nanotubes and hydrogels made by oxidative exfoliation of carbon nanotube ropes," Journal of the American Chemical Society, vol. 125, no. 32, pp. 97619769, 2003.

[74] I. W. Chiang, B. E. Brinson, A. Y. Huang, et al., "Purification and characterization of single-wall carbon nanotubes (SWNTs) obtained from the gas-phase decomposition of CO (HiPco process)," Journal of Physical Chemistry B, vol. 105, no. 35, pp. 8297-8301, 2001.

[75] B. Zhao, H. Hu, A. Yu, D. Perea, and R. C. Haddon, "Synthesis and characterization of water soluble singlewalled carbon nanotube graft copolymers," Journal of the American Chemical Society, vol. 127, no. 22, pp. 8197-8203, 2005.

[76] M. S. Strano, C. A. Dyke, M. L. Usrey, et al., "Electronic structure control of single-waited carbon nanotube functionalization," Science, vol. 301, no. 5639, pp. 1519-1522, 2003.

[77] W. Zhu, N. Minami, S. Kazaoui, and Y. Kim, " $\pi$ chromophore-functionalized SWNTs by covalent bonding: substantial change in the optical spectra proving strong electronic interaction," Journal of Materials Chemistry, vol. 14, no. 13, pp. 1924-1926, 2004.

[78] A. Calzolari, N. Marzari, I. Souza, and M. Buongiorno Nardelli, "Ab initio transport properties of nanostructures from maximally localized Wannier functions," Physical Review B, vol. 69, no. 3, Article ID 035108, 2004.

[79] Y.-S. Lee, M. B. Nardelli, and N. Marzari, "Band structure and quantum conductance of nanostructures from maximally localized Wannier functions: the case of functionalized carbon nanotubes," Physical Review Letters, vol. 95, no. 7, Article ID 076804, 4 pages, 2005.

[80] J. L. Bahr and J. M. Tour, "Covalent chemistry of single-wall carbon nanotubes," Journal of Materials Chemistry, vol. 12, no. 7, pp. 1952-1958, 2002.

[81] Z. Sun, V. Nicolosi, D. Rickard, S. D. Bergin, D. Aherne, and J. N. Coleman, "Quantitative evaluation of surfactantstabilized single-walled carbon nanotubes: dispersion quality and its correlation with zeta potential," Journal of Physical Chemistry C, vol. 112, no. 29, pp. 10692-10699, 2008.
[82] H. Cathcart, S. Quinn, V. Nicolosi, J. M. Kelly, W. J. Blau, and J. N. Coleman, "Spontaneous debundling of singlewalled carbon nanotubes in DNA-based dispersions," Journal of Physical Chemistry C, vol. 111, no. 1, pp. 66-74, 2007.

[83] Y. Noguchi, T. Fujigaya, Y. Niidome, and N. Nakashima, "Single-walled carbon nanotubes/DNA hybrids in water are highly stable," Chemical Physics Letters, vol. 455, no. 4-6, pp. 249-251, 2008.

[84] X. Zhang, T. Liu, T. V. Sreekumar, et al., "Poly(vinylalcohol)/SWNT Composite Film," Nano Letters, vol. 2003, no. 3, p. 1285, 2003.

[85] G. R. Dieckmann, A. B. Dalton, P. A. Johnson, et al., "Controlled assembly of carbon nanotubes by designed amphiphilic peptide helices," Journal of the American Chemical Society, vol. 125, no. 7, pp. 1770-1777, 2003.

[86] V. Zorbas, A. Ortiz-Acevedo, A. B. Dalton, et al., "Preparation and characterization of individual peptide-wrapped singlewalled carbon nanotubes," Journal of the American Chemical Society, vol. 126, no. 23, pp. 7222-7227, 2004.

[87] N. Minami, Y. Kim, K. Miyashita, S. Kazaoui, and B. Nalini, "Cellulose derivatives as excellent dispersants for singlewall carbon nanotubes as demonstrated by absorption and photoluminescence spectroscopy," Applied Physics Letters, vol. 88, no. 9, Article ID 093123, 2006.

[88] P. R. Birkin, D. G. Offin, P. F. Joseph, and T. G. Leighton, "Cavitation, shock waves and the invasive nature of sonoelectrochemistry," Journal of Physical Chemistry B, vol. 109, no. 35, pp. 16997-17005, 2005.

[89] S. M. Bachilo, M. S. Strano, C. Kittrell, R. H. Hauge, R. E. Smalley, and R. B. Weisman, "Structure-assigned optical spectra of single-walled carbon nanotubes," Science, vol. 298, no. 5602, pp. 2361-2366, 2002.

[90] R. Bandyopadhyaya, E. Nativ-Roth, O. Regev, and R. Yerushalmi-Rozen, "Stabilization of individual carbon nanotubes in aqueous solutions," Nano Letters, vol. 2, no. 1, pp. 25-28, 2002.

[91] L. Picton, I. Bataille, and G. Muller, "Analysis of a complex polysaccharide (gum arabic) by multi-angle laser light scattering coupled on-line to size exclusion chromatography and flow field flow fractionation," Carbohydrate Polymers, vol. 42, no. 1, pp. 23-31, 2000.

[92] T. Takahashi, K. Tsunoda, H. Yajima, and T. Ish II, "Dispersion and purification of single-wall carbon nanotubes using carboxymethylcellulose," Japanese Journal of Applied Physics Part 1, vol. 43, no. 6, pp. 3636-3639, 2004.

[93] J. Lefebvre, J. M. Fraser, Y. Homma, and P. Finnie, "Photoluminescence from single-walled carbon nanotubes: a comparison between suspended and micelle-encapsulated nanotubes," Applied Physics A, vol. 78, no. 8, pp. 1107-1110, 2004.

[94] A. Jorio, C. Fantini, M. A. Pimenta, et al., "Carbon nanotube population analysis from Raman and photoluminescence intensities," Applied Physics Letters, vol. 88, no. 2, Article ID 023109, 3 pages, 2006.

[95] A. G. Rinzler, J. Liu, H. Dai, et al., "Large-scale purification of single-wall carbon nanotubes: process, product, and characterization," Applied Physics A, vol. 67, no. 1, pp. 29-37, 1998.

[96] S. M. Bachilo, L. Balzano, J. E. Herrera, F. Pompeo, D. E. Resasco, and R. B. Weisman, "Narrow $(n, m)$-distribution of single-walled carbon nanotubes grown using a solid supported catalyst," Journal of the American Chemical Society, vol. 125, no. 37, pp. 11186-11187, 2003. 
[97] R. B. Weisman, S. M. Bachilo, and D. Tsyboulski, "Fluorescence spectroscopy of single-walled carbon nanotubes in aqueous suspension," Applied Physics A, vol. 78, no. 8, pp. 1111-1116, 2004.

[98] O. Kiowski, S. Lebedkin, F. Hennrich, et al., "Photoluminescence microscopy of carbon nanotubes grown by chemical vapor deposition: influence of external dielectric screening on optical transition energies," Physical Review B, vol. 75, no. 7, Article ID 075422, 2007.

[99] A. M. Rao, E. Richter, S. Bandow, et al., "Diameterselective Raman scattering from vibrational modes in carbon nanotubes," Science, vol. 275, no. 5297, pp. 187-190, 1997.

[100] T. Hasan, V. Scardaci, P. Tan, A. G. Rozhin, W. I. Milne, and A. C. Ferrari, "Stabilization and "debundling" of single-wall carbon nanotube dispersions in N-methyl-2-pyrrolidone (NMP) by polyvinylpyrrolidone (PVP)," Journal of Physical Chemistry C, vol. 111, no. 34, pp. 12594-12602, 2007.

[101] T. Hasan, P. H. Tan, F. Bonaccorso, et al., "Polymer-assisted isolation of single wall carbon nanotubes in organic solvents for optical-quality nanotube-polymer composites," Journal of Physical Chemistry C, vol. 112, no. 51, pp. 20227-20232, 2008.

[102] A. Hagen and T. Hertel, "Quantitative Analysis of Optical Spectra from Individual Single-Wall Carbon Nanotubes," Nano Letters, vol. 3, p. 383, 2003.

[103] A. G. Walsh, A. N. Vamivakas, Y. Yin, et al., "Screening of excitons in single, suspended carbon nanotubes," Nano Letters, vol. 7, no. 6, pp. 1485-1488, 2007.

[104] J. Kong, N. R. Franklin, C. Zhou, et al., "Nanotube molecular wires as chemical sensors," Science, vol. 287, no. 5453, pp. 622-625, 2000.

[105] J. Maultzsch, H. Telg, S. Reich, and C. Thomsen, "Radial breathing mode of single-walled carbon nanotubes: optical transition energies and chiral-index assignment," Physical Review B, vol. 72, no. 20, 16 pages, 2005.

[106] P. H. Tan, A. G. Rozhin, T. Hasan, et al., "Photoluminescence spectroscopy of carbon nanotube bundles: evidence for exciton energy transfer," Physics Review Letters, vol. 99, Article ID 137402, 4 pages, 2007.

[107] P. H. Tan, T. Hasan, F. Bonaccorso, et al., "Optical properties of nanotube bundles by photoluminescence excitation and absorption spectroscopy," Physica E, vol. 40, no. 7, pp. 23522359, 2008.

[108] V. Perebeinos, J. Tersoff, and P. Avouris, "Effect of excitonphonon coupling in the calculated optical absorption of carbon nanotubes," Physical Review Letters, vol. 94, no. 2, Article ID 027402, 4 pages, 2005.

[109] F. Plentz, H. B. Ribeiro, A. Jorio, M. S. Strano, and M. A. Pimenta, "Direct experimental evidence of exciton-phonon bound states in carbon nanotubes," Physical Review Letters, vol. 95, no. 24, Article ID 247401, 2005.

[110] J. Lefebvre and P. Finnie, "Polarized photoluminescence excitation spectroscopy of single-walled carbon nanotubes," Physics Review Letters, vol. 98, Article ID 167406, 4 pages, 2007.

[111] T. Kato and R. Hatakeyama, "Exciton energy transfer-assisted photoluminescence brightening from freestanding singlewalled carbon nanotube bundles," Journal of the American Chemical Society, vol. 130, no. 25, pp. 8101-8107, 2008.

[112] O. N. Torrens, M. Zheng, and J. M. Kikkawa, "Energy of Kmomentum dark excitons in carbon nanotubes by optical spectroscopy," Physical Review Letters, vol. 101, no. 15, Article ID 157401, 2008.
[113] H. Qian, C. Georgi, N. Anderson, et al., "Exciton energy transfer in pairs of single-walled carbon nanotubes," Nano Letters, vol. 8, no. 5, pp. 1363-1367, 2008.

[114] S. Reich, C. Thomsen, and J. Robertson, "Exciton resonances quench the photoluminescence of zigzag carbon nanotubes," Physical Review Letters, vol. 95, no. 7, Article ID 077402, 4 pages, 2005.

[115] H. Telg, J. Maultzsch, S. Reich, F. Hennrich, and C. Thomsen, "Erratum: chirality distribution and transition energies of carbon nanotubes," Physical Review Letters, vol. 93, no. 18, Article ID 177401, 2004.

[116] J. C. Meyer, M. Paillet, T. Michel, et al., "Raman modes of index-identified freestanding single-walled carbon nanotubes," Physical Review Letters, vol. 95, no. 21, 4 pages, 2005.

[117] A. Jorio, R. Saito, J. H. Hafner, et al., "Structural $(n, m)$ determination of isolated single-wall carbon nanotubes by resonant Raman scattering," Physical Review Letters, vol. 86, no. 6, pp. 1118-1121, 2001.

[118] M. Paillet, T. Michel, J. C. Meyer, et al., "Raman active phonons of identified semiconducting single-walled carbon nanotubes," Physical Review Letters, vol. 96, no. 25, Article ID 257401, 2006.

[119] P. T. Araujo, S. K. Doorn, S. Kilina, et al., "Third and fourth optical transitions in semiconducting carbon nanotubes," Physical Review Letters, vol. 98, no. 6, Article ID 067401, 2007.

[120] H. Kataura, Y. Kumazawa, Y. Maniwa, et al., "Optical properties of single-wall carbon nanotubes," Synthetic Metals, vol. 103, no. 1-3, pp. 2555-2558, 1999.

[121] A. C. Ferrari and J. Robertson, "Interpretation of Raman spectra of disordered and amorphous carbon," Physical Review B, vol. 61, no. 20, pp. 14095-14107, 2000.

[122] A. C. Ferrari and J. Robertson, "Resonant Raman spectroscopy of disordered, amorphous, and diamondlike carbon," Physical Review B, vol. 64, Article ID 075414, 13 pages, 2001.

[123] A. C. Ferrari, "Raman spectroscopy of graphene and graphite: Disorder, electron-phonon coupling, doping and nonadiabatic effects," Solid State Communications, vol. 143, p. 47, 2007.

[124] M. Lazzeri, S. Piscanec, F. Mauri, A. C. Ferrari, and J. Robertson, "Phonon linewidths and electron-phonon coupling in graphite and nanotubes," Physical Review B, vol. 73, no. 15, Article ID 155426, 2006.

[125] S. Piscanec, M. Lazzeri, J. Robertson, A. C. Ferrari, and F. Mauri, "Optical phonons in carbon nanotubes: kohn anomalies, peierls distortions, and dynamic effects," Physical Review B, vol. 75, no. 3, Article ID 035427, 2007.

[126] A. C. Ferrari, J. C. Meyer, V. Scardaci, et al., "Raman spectrum of graphene and graphene layers," Physical Review Letters, vol. 97, Article ID 187401, 4 pages, 2006.

[127] T. M. G. Mohiuddin, A. Lombardo, R. R. Nair, et al., "Uniaxial strain in graphene by Raman spectroscopy: G peak splitting, Grüneisen parameters, and sample orientation," Physical Review B, vol. 79, Article ID 205433, 8 pages, 2009.

[128] A. Das, A. K. Sood, A. Govindaraj, et al., "Doping in carbon nanotubes probed by Raman and transport measurements," Physical Review Letters, vol. 99, no. 13, Article ID 136803, 2007.

[129] J. C. Tsang, M. Freitag, V. Perebeinos, J. Liu, and P. H. Avouris, "Doping and phonon renormalization in carbon nanotubes," Nature Nanotechnology, vol. 2, no. 11, pp. 725730, 2007. 
[130] A. Das, S. Pisana, B. Chakraborty, et al., "Monitoring dopants by Raman scattering in an electrochemically topgated graphene transistor," Nature Nanotechnology, vol. 3, no. 4, pp. 210-215, 2008.

[131] C. Fantini, A. Jorio, M. Souza, M. S. Strano, M. S. Dresselhaus, and M. A. Pimenta, "Optical transition energies for carbon nanotubes from resonant raman spectroscopy: environment and temperature effects," Physical Review Letters, vol. 93, no. 14, Article ID 147406, 4 pages, 2004.

[132] T. Svedberg and K. O. Pedersen, The Ultracentrifuge, 1940.

[133] R. Westermeier, Electrophoresis in Practice, Wiley-VCH, Weinheim, Germany, 2005.

[134] S. Ahuja, "Separation Science and Technology," in Handbook of Bioseparations, S. Ahuja, Ed., vol. 1, Academic Press, San Diego, Calif, USA, 2000.

[135] M. C. Hersam, "Progress towards monodisperse singlewalled carbon nanotubes," Nature Nanotechnology, vol. 3, no. 7, pp. 387-394, 2008.

[136] F. Bonaccorso, T. Hasan, P. H. Tan, et al., submitted.

[137] J. L. Kwo, M. Yokoyama, W. C. Wang, F. Y. Chuang, and I. N. Lin, "Characteristics of flat panel display using carbon nanotubes as electron emitters," Diamond and Related Materials, vol. 9, no. 3, pp. 1270-1274, 2000.

[138] Q. H. Wang, M. Yan, and R. P. H. Chang, "Flat panel display prototype using gated carbon nanotube field emitters," Applied Physics Letters, vol. 78, no. 9, pp. 1294-1296, 2001.

[139] I. Hamberg and C. G. Granqvist, "Evaporated Sn-doped $\mathrm{In}_{2} \mathrm{O}_{3}$ films: basic optical properties and applications to energy-efficient windows," Journal of Applied Physics, vol. 60, no. 11, pp. R123-R160, 1986.

[140] K. Nomura, H. Ohta, K. Ueda, T. Kamiya, M. Hirano, and H. Hosono, "Thin-film transistor fabricated in single-crystalline transparent oxide semiconductor," Science, vol. 300, no. 5623, pp. 1269-1272, 2003.

[141] J.-Y. Lee, S. T. Connor, Y. Cui, and P. Peumans, "Solutionprocessed metal nanowire mesh transparent electrodes," Nano Letters, vol. 8, no. 2, pp. 689-692, 2008.

[142] F. Yang and S. R. Forrest, "Organic solar cells using transparent $\mathrm{SnO}_{2}-\mathrm{F}$ anodes," Advanced Materials, vol. 18, no. 15, pp. 2018-2022, 2006.

[143] J. Meiss, M. K. Riede, and K. Leo, "Towards efficient tindoped indium oxide (ITO)-free inverted organic solar cells using metal cathodes," Applied Physics Letters, vol. 94, no. 1, Article ID 013303, 3 pages, 2009.

[144] B. O'Connor, C. Haughn, K.-H. An, K. P. Pipe, and M. Shtein, "Transparent and conductive electrodes based on unpatterned, thin metal films," Applied Physics Letters, vol. 93, Article ID 223304, p. 22, 2008.

[145] S. De, T. M. Higgins, P. E. Lyons, et al., "Silver nanowire networks as flexible, transparent, conducting films: extremely high DC to optical conductivity ratios," ACS Nano, vol. 3, no. 7, pp. 1767-1774, 2009.

[146] M. G. Kang, M.-S. Kim, J. Kim, and L. Jay Guo, "organic solar cells using nanoimprinted transparent metal electrodes," Advanced Materials, vol. 20, pp. 4408-4413, 2008.

[147] Z. Wu, Z. Chen, X. Du, et al., "Transparent, conductive carbon nanotube films," Science, vol. 305, no. 5688, pp. 1273 1276, 2004.

[148] H.-Z. Geng, K. K. Kim, K. P. So, Y. S. Lee, Y. Chang, and Y. H. Lee, "Effect of acid treatment on carbon nanotubebased flexible transparent conducting films," Journal of the
American Chemical Society, vol. 129, no. 25, pp. 7758-7759, 2007.

[149] B. B. Parekh, G. Fanchini, G. Eda, and M. Chhowalla, "Improved conductivity of transparent single-wall carbon nanotube thin films via stable postdeposition functionalization," Applied Physics Letters, vol. 90, no. 12, Article ID 121913, 2007.

[150] P. N. Nirmalraj, P. E. Lyons, S. De, J. N. Coleman, and J. J. Boland, "Electrical connectivity in single-walled carbon nanotube networks," Nano Letters, vol. 9, no. 11, pp. 3890$3895,2009$.

[151] Y. Zhou, L. Hu, and G. Grüner, "A method of printing carbon nanotube thin films," Applied Physics Letters, vol. 88, Article ID 123109, 2006.

[152] L. Hu, et al., "patternable transparent carbon nanotube film for electrochromic devices," Journal of Applied Physics, vol. 101, Article ID 016102, 2007.

[153] G. Grüner, "Carbon nanotube films for transparent and plastic electronics," Journal of Materials Chemistry, vol. 16, no. 35, pp. 3533-3539, 2006.

[154] L. Hu, D. S. Hecht, and G. Grüner, "Percolation in transparent and conducting carbon nanotube networks," Nano Letters, vol. 4, no. 12, pp. 2513-2517, 2004.

[155] J. H. Yim, Y. S. Kim, K. H. Koh, and S. Lee, "Fabrication of transparent single wall carbon nanotube films with low sheet resistance," Journal of Vacuum Science and Technology B, vol. 26, no. 2, pp. 851-855, 2008.

[156] B. Dan, G. C. Irvin, and M. Pasquali, "Continuous and scalable fabrication of transparent conducting carbon nanotube films," ACS Nano, vol. 3, no. 4, pp. 835-843, 2009.

[157] S. De, P. E. Lyons, S. Sorel, et al., "Transparent, flexible, and highly conductive thin films based on polymer-nanotube composites," ACS Nano, vol. 3, no. 3, pp. 714-720, 2009.

[158] G. F. Wang, X. M. Tao, and R. X. Wang, "Flexible organic light-emitting diodes with a polymeric nanocomposite anode," Nanotechnology, vol. 19, Article ID 145201, 2008.

[159] T. Mustonen, K. Kordás, S. Saukko, et al., "Inkjet printing of transparent and conductive patterns of single-walled carbon nanotubes and PEDOT-PSS composites," Physica Status Solidi B, vol. 244, no. 11, pp. 4336-4340, 2007.

[160] H. Gu and T. M. Swager, "Fabrication of free-standing, conductive, and transparent carbon nanotube films," Advanced Materials, vol. 20, pp. 234433-4437, 2008.

[161] I. O'Connor, S. De, J. N. Coleman, and Y. K. Gun'ko, "Development of transparent, conducting composites by surface infiltration of nanotubes into commercial polymer films," Carbon, vol. 47, no. 8, pp. 1983-1988, 2009.

[162] B. S. Shim, Z. Tang, M. P. Morabito, A. Agarwal, H. Hong, and N. A. Kotov, "Integration of conductivity, transparency, and mechanical strength into highly homogeneous layerby-layer composites of single-walled carbon nanotubes for optoelectronics," Chemistry of Materials, vol. 19, no. 23, pp. 5467-5474, 2007.

[163] M. S. P. Shaffer and A. H. Windle, "Fabrication and characterization of carbon nanotube/poly(vinyl alcohol) composites," Advanced Materials, vol. 11, no. 11, pp. 937941, 1999.

[164] H. Guo, T. V. Sreekumar, T. Liu, M. Minus, and S. Kumar, "Structure and properties of polyacrylonitrile/single wall carbon nanotube composite films," Polymer, vol. 46, no. 9, pp. 3001-3005, 2005. 
[165] S. Bae, H. K. Kim, Y. Lee, et al., 10.1038/NNANO.2010.132, (2010).

[166] A. A. Green and M. C. Hersam, "Solution phase production of graphene with controlled thickness via density differentiation," Nano Letters, vol. 9, no. 12, pp. 4031-4036, 2009.

[167] S. Anandan, "Recent improvements and arising challenges in dye-sensitized solar cells," Solar Energy Materials and Solar Cells, vol. 91, no. 9, pp. 843-846, 2007.

[168] B.-K. Koo, D.-Y. Lee, H.-J. Kim, W.-J. Lee, J.-S. Song, and H.-J. Kim, "Seasoning effect of dye-sensitized solar cells with different counter electrodes," Journal of Electroceramics, vol. 17, no. 1, pp. 79-82, 2006.

[169] H. S. Wroblowa and A. Saunders, "Flow-through electrodes. II. The $\mathrm{I}_{3}^{-} / \mathrm{I}^{-}$redox couple," Journal of Electroanalytical Chemistry, vol. 42, no. 3, pp. 329-346, 1973.

[170] A. Kay and M. Grätzel, "Low cost photovoltaic modules based on dye sensitized nanocrystalline titanium dioxide and carbon powder," Solar Energy Materials and Solar Cells, vol. 44, no. 1, pp. 99-117, 1996.

[171] W. J. Lee, E. Ramasamy, D. Y. Lee, and J. S. Song, "efficient dye-sensitized solar cells with catalytic multiwall carbon nanotube counter electrodes," Applied Materials, vol. 6, pp. 1145-1149, 2009.

[172] X. Fang, T. Ma, M. Akiyama, G. Guan, S. Tsunematsu, and E. Abe, "Flexible counter electrodes based on metal sheet and polymer film for dye-sensitized solar cells," Thin Solid Films, vol. 472, no. 1-2, pp. 242-245, 2005.

[173] S.-R. Jang, R. Vittal, and K.-J. Kim, "Incorporation of functionalized single-wall carbon nanotubes in dye-sensitized $\mathrm{TiO}_{2}$ solar cells," Langmuir, vol. 20, no. 22, pp. 9807-9810, 2004.

[174] T. Y. Lee, P. S. Alegaonkar, and J.-B. Yoo, "Fabrication of dye sensitized solar cell using $\mathrm{TiO}_{2}$ coated carbon nanotubes," Thin Solid Films, vol. 515, no. 12, pp. 5131-5135, 2007.

[175] N. Yang, J. Zhai, D. Wang, Y. Chen, and L. Jiang, "Twodimensional graphene bridges enhanced photoinduced charge transport in dye-sensitized solar cells," ACS Nano, vol. 4, no. 2, pp. 887-894, 2010.

[176] M. Shiraishi and M. Ata, "Work function of carbon nanotubes," Carbon, vol. 39, no. 12, pp. 1913-1917, 2001. 


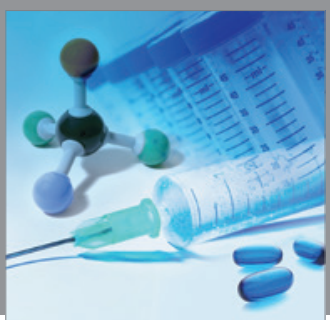

International Journal of

Medicinal Chemistry

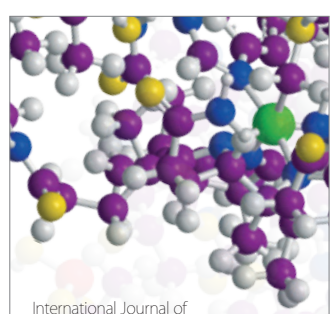

Carbohydrate Chemistry

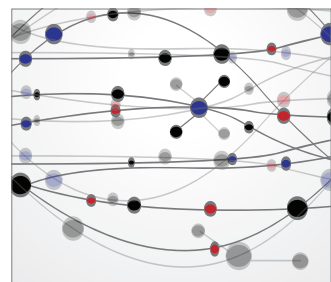

The Scientific World Journal
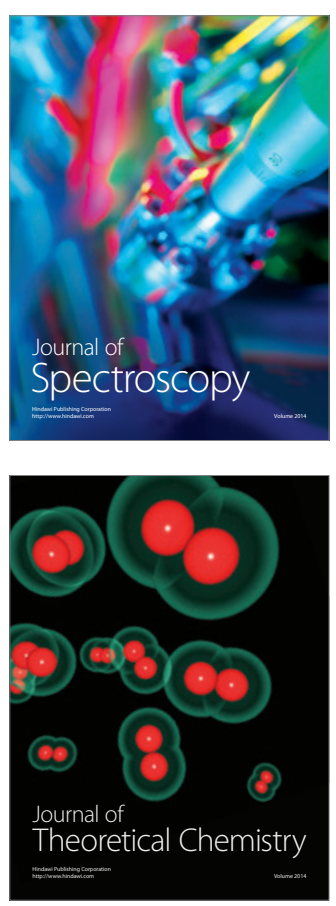
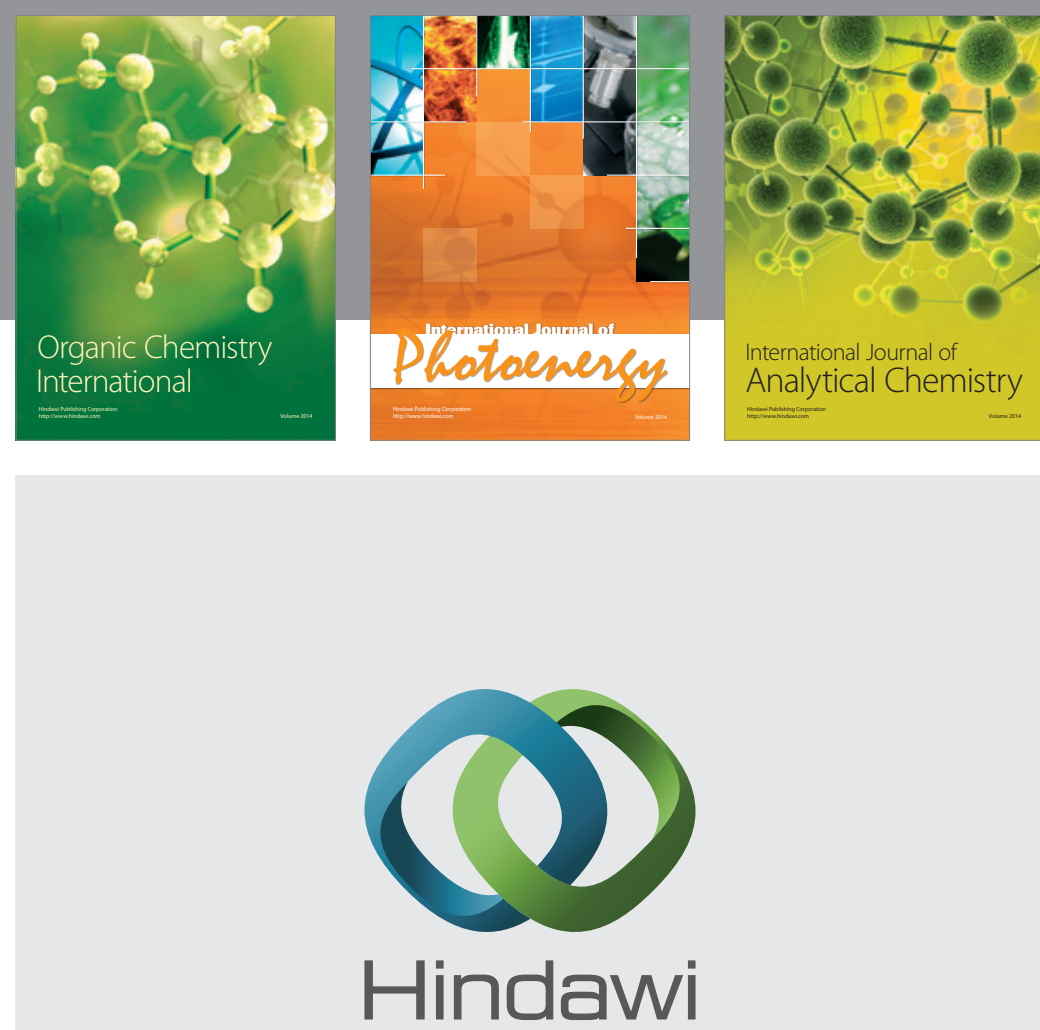

Submit your manuscripts at

http://www.hindawi.com
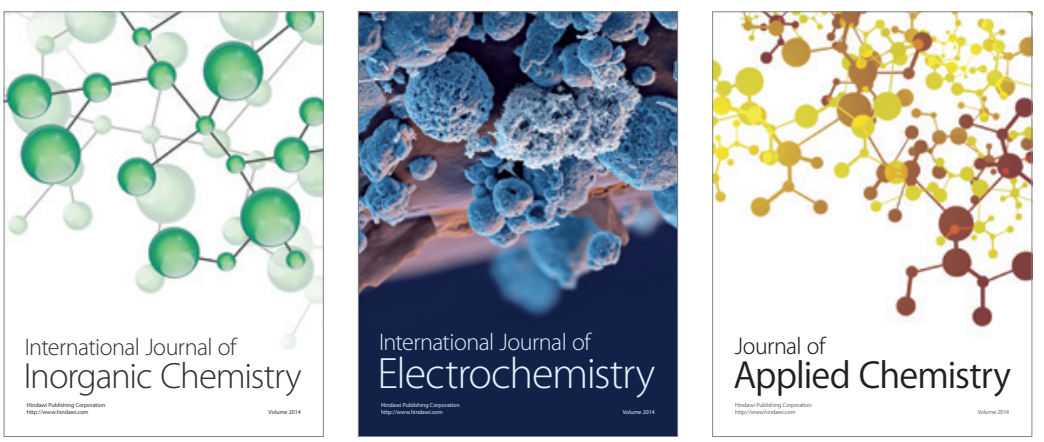

Journal of

Applied Chemistry
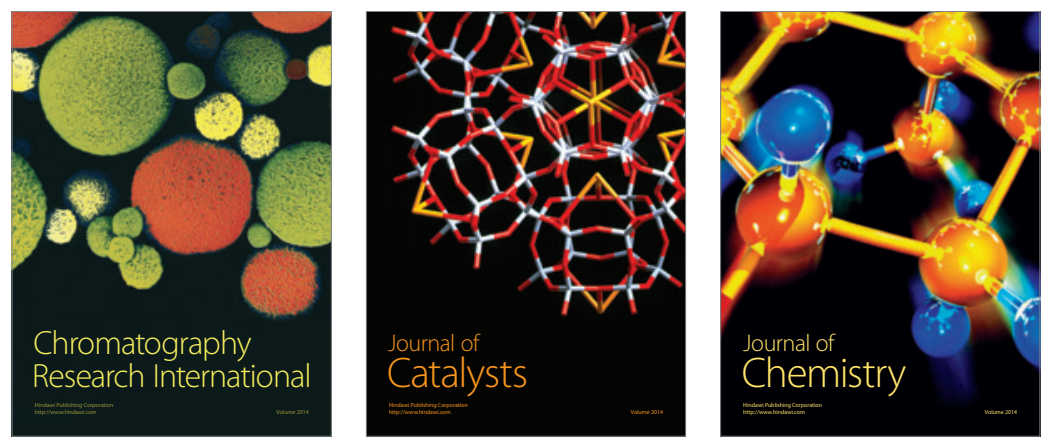
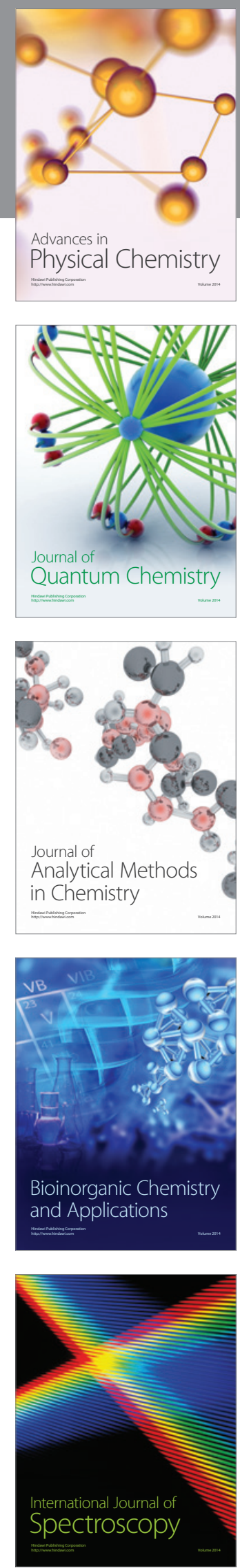